\title{
Introducing human rights and health into a nursing curriculum
}

\author{
P Mayers, MSc Med (Psych) \\ Senior Lecturer, Division of Nursing and Midwifery, School of Health and Rehabilitation Sciences, University of \\ Cape Town
}

\section{Keywords:}

Health and human rights; human rights education; nurses; nursing education

\section{Correspondence address:}

F45 Old Main Building

Groote Schuur Hospital

Observatory 7925

South Africa

Tel : (021) 406-6464

Fax : (021) 406-6323

E-mail : Pat.Mayers@uct.ac.za

\section{Abstract: Curationis 30(4): 53-60 \\ Aim}

The introduction of a module in Health and Human Rights into a Postgraduate diploma curriculum for registered nurses is described.

\section{Background}

An important component of nursing programmes in South Africa has been teaching of the principles of ethical practice and relevant ethical codes. A number of factors have contributed to the need to include human rights as an integral component of nursing curricula in South Africa. These include the Bill of Rights in the Constitution of South Africa and the implications thereof for health care delivery, the primary health care approach in the delivery of health care in South Africa, the development and acceptance of Patients' Rights Charters, and the recognition of the role that health professionals played - whether through lack of knowledge and awareness or direct involvement - in the human rights violations in the health sector exposed during the hearings of the Truth and Reconciliation Commission.

\section{Module description}

An outline of themes covered in the course content is described, together with examples of learning activities and teaching materials.

Reflections of the course convenor and students are used to highlight the importance of inclusion of health and human rights as foundational to ethical nursing practice, regardless of the health care setting.

\section{Introduction and background}

"Nursing shares with other health professionals a commitment to the well-being of the patient and to a professional practice based on codes of ethics" (Amnesty International, 1997: 1).

Historically, nurses have played an important role in health care provision and in upholding humane values in the care of their patients. An important component of nursing programme curricula in South Africa has been teaching of the principles of ethical practice and the relevant ethical codes.

Human rights, which include the right to health and access to health care and refer to essential social determinants of health and well-being of people, overlap with the principles and norms of bioethics (Marks, 2003: 1). Wildschut, in a paper presented to the International Council of Nurses Ethics Conference in 2001, stated: "Awareness of human rights is crucial for nurses, as they are often at the forefront of critical decisions and procedures and are able to see the immediate effects on patients and their relatives of human rights violations" (2001: 1). From the recommendations made by the Truth and Reconciliation Commission (TRC) it is clear that health professionals have an ethical obligation to place the well-being of their patients at the forefront of their professional 
commitments (The Truth and Reconciliation Commission, 2002: v. 5, 334-40).

A number of factors contributed to the need to include human rights as an integral component of nursing curricula in South Africa. These included the Bill of Rights in the Constitution of South Africa Act No. 108 of 1996 (South Africa (Republic), 1996) and the implications thereof for health care delivery; the primary health care approach in the delivery of health care in South Africa as stipulated in the National Health Act No. 61 of 2003 (South Africa (Republic)), the development and acceptance of the $\mathrm{Pa}$ tients' Rights Charter (National Department of Health South Africa, 2002), and the recognition of the role that health professionals played - through lack of knowledge and awareness or direct involvement and complicity - in the human rights violations in the health sector exposed during the hearings of the TRC (Baldwin-Ragaven, London and de Gruchy, 2000: 230-32; London and Baldwin-Ragaven, 2006: 20).

During the apartheid years there were many incidents in which health professionals were complicit in the violation of the human rights of persons in their care. Medical doctors in particular played a controversial role in the detention and torture of political activists (BaldwinRagaven, de Gruchy and London, 1999: 91-118). Baldwin-Ragaven et al. (1999:91) make a distinction between active participation in the torture and abuse of prisoners and detainees and collusion (either active or passive) resulting in the violation of human rights. Although the role of other health professionals in human rights violations in South Africa was not as fully documented, the TRC found that "the health sector, through apathy, acceptance of the status quo and acts of omission, allowed the creation of an environment in which the health of millions of South Africans was neglected, even at times actively compromised, and in which violation of ethical codes of practice were frequent, facilitating violations of human rights" (The Truth and Reconciliation Commission, $2002 \mathrm{v}$. 5:250).

As frontline health care providers during the years of the apartheid regime in South Africa, nurses not only had to deal with consequences of the violation of the human rights of their patients, but were seldom able to challenge the State about these abuses.

Ethical codes regulate professional conduct and provide a standard by which the behaviour of health professionals can be evaluated in their role of protecting the public from harm. However, these codes do not adequately assist the health professional in dealing with abuses such as those which occurred under the apartheid regime (Steere and Dowdall, 1990: 14). Violation of the rights of patients included reporting injured persons to the security forces, permitting security forces to compromise the care of patients, failing to accurately record a patient's condition, breaking confidentiality and failing to act as the patient's advocate. Both the South African Nursing Council (1997: 3-5) and the Democratic Nurses Organisation of South Africa (DENOSA) (1997: 3-4) (which replaced the South African Nursing Association), in their submissions to the TRC accepted responsibility for the part that nurses played in violating the rights of patients under apartheid. These bodies committed themselves to promoting human rights in nursing curricula and promoting awareness among nurse educators. In its final report the TRC (2002 v. 5: 334 40) made fifty-six recommendations in order to prevent human rights abuses within the health sector, and emphasised the importance of inclusion of human rights education for health professionals.

The linkages between health and human rights are inextricable and complex. Mann, Gostin, Gruskin, Brennan, Lazzarini and Fineberg (1999: 11-17) offer a three-part framework for considering these, and argue that: (i) health policies and programmes may have beneficial or adverse impacts on human rights, particularly in public health; (ii) health care practices and health care research may inadvertently violate human rights; and (iii) violations of human rights may have adverse health effects on individuals and groups.

Health professionals are challenged by dual loyalty conflicts which may violate patients' rights (Steere and Dowdall, 1990: 12, 14; Rubenstein, 2003: 270). Nurses and midwives not only face increasingly complex ethical decisions in the workplace, but deal daily with human rights issues. They are also increasingly at risk of violence in their work environments, and it is therefore crucial that they have access to human rights education in order to promote a human rights ethos in the workplace and to protect their own rights (International Council of Nurses, 2001: 1; Amnesty International, 2005: 650). Amnesty International calls for a stronger human rights role for nurses and midwives, which in turn would "strengthen nurses' capacity to protect the rights and interests of patients and contribute to a more just society" (2005: 649).

Vulnerability and the impact of ill-health can be minimised by taking appropriate steps to respect, protect and fulfil human rights (World Health Organization, 2001: 7). The promotion of human rights is therefore an essential part of efforts to promote and protect public health (Hannibal and Lawrence, 1999: 412; Mann et al., 1999: 14; 16). Health professionals should learn about human rights in order to protect rights through identifying, documenting and testifying about rights violations (Austin, 2001: 192-3).

The adoption by the United Nations General Assembly of the Universal Declaration of Human Rights in 1948 provided a fundamental reference point and laid the cornerstone of the modern human rights movement. The standards set by the Declaration were not considered legally binding, but rather as goals towards which nations that subscribed to the Declaration could strive. There are numerous codes and declarations which have emanated from this initial movement which are now regarded as fundamental to the manner in which human beings should be treated. These treaties and codes have implications for nurses and midwives, and include the: International Covenant on Civil and Political Rights and International Covenant on Economic, Social and Cultural Rights (United Nations, 1966); Convention on the Rights of the Child (United Nations General Assembly, 1989); Convention on the Elimination of all Forms of Discrimination against Women (CEDAW) (United Nations General Assembly, 1979) and Declaration on the Rights of Disabled Persons (United Nations General Assembly, 1975).

\section{The Features of Human Rights}

The main features of human rights have been identified as follows (International Federation of Red Cross and Red Crescent Societies and François-Xavier 
Bagnoud Center for Health and Human Rights, 1999:21-2; Gruskin and Tarantola, 2002:313):

- $\quad$ people have rights simply because they are human;

- these rights cannot be earned, nor lost for bad behaviour;

- they encompass the fundamental principles of humanity;

- they are universal - with no account of race, gender or colour;

- $\quad$ they treat all people as equal all human beings are born free and equal in rights and dignity" (Universal Declaration of Human Rights Article 1) (United Nations, 948) - and people therefore deserve the same opportunities and treatment, while respecting their different cultures and traditions, political persuasion, sexuality, social origin, status, etc.;

- $\quad$ rights belong primarily to individuals, addressing directly the relationship between governments and individuals. Consequently it is for the government to create a society where each in dividual can enjoy and freely exercise his/her rights to the full;

- the promotion and protection of human rights is not bounded by national boundaries.

Incorporation of the Bill of Rights in South Africa's first democratic Constitution (Act No. 108 of 1996) for the first time gave the country a document which determines the rights of individuals and groups/communities. These rights have far-reaching implications for health professionals, and particularly for nurses and midwives since they form the largest body of health professionals in the country and interact with clients and patients at all levels of care. London and BaldwinRagaven (2006: 21-22) identify these rights as: "the right to receive health care services; rights related to the underlying conditions for health, which through their fulfilment, enhance health; rights for vulnerable groups and foundational rights that acknowledge our common humanity and principles of equity".

\section{Health and Human Rights}

Health as a human right has its roots in the public health movement of the $19^{\text {th }}$ century (Mann, 1999: 439- 41; Hassim, Heywood \& Berger, 2007: 7). The right to health was first formally recognised in 1946 when the Constitution of the World Health Organization was adopted, which states: "The enjoyment and exercise of all human rights affects the health of individuals. This is especially evident when considering the modern definition of health 'as a state of complete physical, mental or social well-being, not merely the absence of disease or infirmity'" (World Health Organization, 1986 [online]). Chapman (1994: 7) defines the right to health care as "a right to a basic and adequate standard of health care consistent with societal resources". This right is inclusive of freedoms such as the right to be free from discrimination and involuntary medical treatment, includes entitlements such as the right to essential primary health care, and extends to the underlying determinants of health such as access to safe water and adequate nutrition (World Health Organization, 2001: 11; Hunt, 2002: 8). "The right requires an effective, inclusive health system of good quality" (Hunt, 2006: 604).

The rights to health and health care are evident in a number of key international instruments on human rights, and are also enshrined in numerous national constitutions (Hunt, 2006: 603). The most important provision on the right to health is Article 12 of the International Covenant on Economic, Social and Cultural Rights, which recognises "the right of everyone to the enjoyment of the highest standard of physical and mental health", and further identifies measures that the State should take in order for individuals to achieve full realisation of this right (United Nations, 1966: Article 12). Article 25 of the United Nations Declaration on Human Rights emphasises the recognition of the rights of all persons to an adequate standard of living, which includes guarantees for health and well-being (1948: Article 25).

Article 16 of the African Charter on $\mathrm{Hu}$ man and People's Rights (Organisation of African Unity (OAU), 1981) refers to the right of every individual to enjoy the best attainable state of physical and mental health. Similarly, the right to health and health services for children is provided for in the Convention of the Rights of the Child (United Nations General Assembly, 1989) as well as the African Charter on the Rights and Welfare of the Child
(Organisation of African Unity (OAU), 1990). CEDAW calls upon states to provide access for women to health and medical care, including access to family planning services (United Nations General Assembly, 1979). The universal recognition of the right to health was clearly stated in the Declaration of Alma-Ata (World Health Organization, 1978), which outlined the basis for states to develop comprehensive health care, based on the primary health care approach, to ensure equitable distribution of resources for the maintenance of health. The South African Constitution places obligations on the State to progressively realise the right of access to health care within its available resources.

Despite the many documents and charters which link health and human rights, many persons continue to experience a lack of acknowledgement of their human rights when dealing with heath care providers. Examples of this include health policies which violate rights, discriminatory practices which threaten physical and mental health, lack of access to health care, maltreatment of women during confinement, denial of dignity, unethical research practices and denial of freedom of expression (Physicians for Human Rights, no date online).

\section{Training in Health and Human Rights}

Health professionals constitute an essential element to ensuring fulfilment of the right to health (World Health Organization, 2002: 9). Training in medical ethics and human rights has been identified by the medical profession as one of the key strategies for prevention of human rights abuses in the health care service (London \& McCarthy, 1998: 257-62). London and McCarthy (1998: 257-62) further state that despite calls for the medical profession to be proactive in teaching medical ethics and human rights, it is only recently that opportunities have arisen for this to be put on the curriculum agendas of institutions responsible for training health professionals.

Among the recommendations of the South African TRC (2002 v.5: 335) was that of training of health professionals: "Training in human rights should be a fundamental and integral aspect of all curricula for health professionals. This training should address factors affecting human rights practice, such as 


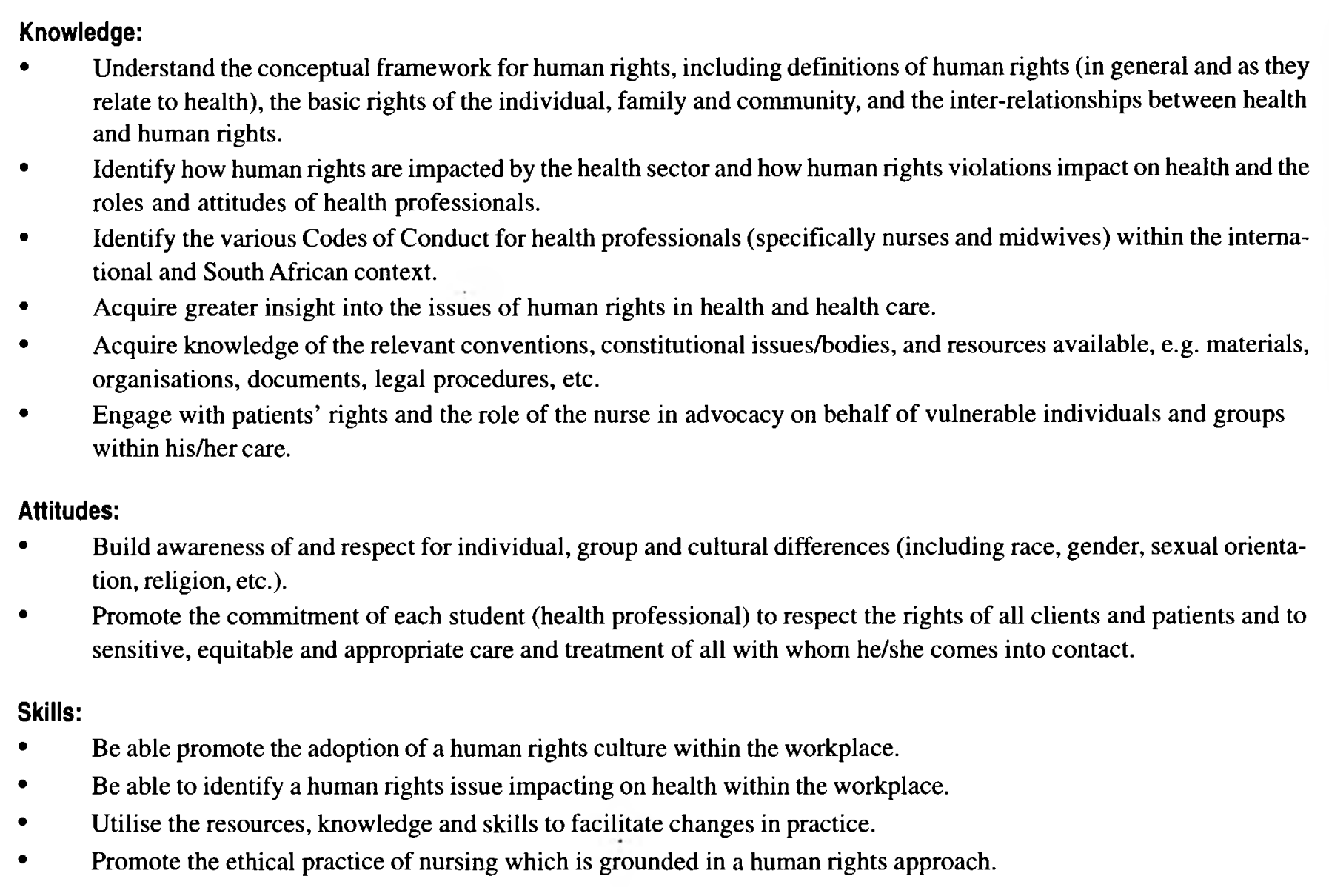

knowledge skills and attitudes and ethical research practices...". Health professionals need to be accountable for their actions, in particular for those which impact on the human rights of the person for whom they care. BaldwinRagaven et al. (2000: 235-6) offer five core objectives for professional accountability in protecting human rights:

- To enunciate/prioritise accountability to patient, to selves, and to society. In providing a more holistic view of health care, this can develop a shared culture of respect for human rights;

- $\quad$ To be able to identify abuses and operationalise human rights tenets;

- $\quad$ To treat patients with dignity and respect; recognise and empower vulnerable groups;

- To re-orientate practice toward a larger social and political context; and

- $\quad$ To clarify values and be aware of conflicting loyalties.

Nurses and midwives need to understand the links between health and human rights (Thompson, 2004: 179). While having given appropriate emphasis to ethos and professional practice and ethics, nursing curricula have not paid sufficient attention to human rights and in particular to the relationship between health and human rights. Hence the training in human rights issues which can occur throughout a nursing curriculum (Chamberlain, 2001: 214) was omitted from the training programmes of the majority of South African nurses who completed their training prior to the mid-1990s. With the advent of democracy in 1994, the enshrining of the Bill of Rights in the South African Constitution, and the commitment of the South African government to creating a human rights culture, it has become crucial for nurses and midwives to engage with human rights as these impact on health and nursing practice.

In attempting to meet the challenges of a human rights culture, a module of 24 hours contact time in health and human rights was introduced as a fundamental module in the Postgraduate Diploma for Registered Nurses programme at the University of Cape Town. As a funda- mental module, the content integrates with and supports the learning objectives of modules in the clinical nursing specialties. Thus all graduates of this programme, whether in advanced midwifery, child nursing, nursing management or other specialties, will have been exposed to this module.

The task of setting up a new curriculum for a Health and Human Rights Module proved challenging, and significant consultation and research went into establishing the module learning objectives (Table 1), content and learning activities. In a country in which the human rights of the majority of the population have long been denied or violated, it was recognised that the introduction of such a module was bound to raise sensitive issues for the convenors as well as the students.

\section{Health and Human Rights Module: Aim and learning outcomes}

The module focuses on the relationship between health and human rights and attempts to address the following ques- 
tions:

- How does one define and under stand human rights?

- What is the basis for human rights concerns among health professionals?

- $\quad$ How can health professionals improve individual and community health by protecting and promoting human rights?

(Amnesty International, 1997 : first screen)

The field of human rights literature is vast, and the task of distilling this to identify the appropriate content for postgraduate nursing students proved challenging. The module deals with sensitive issues and planning therefore had to take into account time for "debriefing" and closure of the topic for the day.

\section{Module description and outline}

The module is divided into sessions of 2-3 hours. Each session deals with a theme or sub-theme. The themes included in the module attempt to provide the student with an overview of the issues while remaining practical through the use of case studies and practical assignments. In an introductory session the student is introduced to the core principles of human rights and given a brief background to the development of human rights in South Africa. The major codes and documentation relating to human rights are examined - including the Universal Declaration of Human Rights, the South African Constitution and Bill of Rights, the African Charter on Human and People's Rights and other international codes relating to health and human rights.

A second theme on Health and Human Rights in South Africa challenges students to confront the past human rights violations and the impact of these on health, and in particular the role of the health sector under the apartheid regime. Transcripts from the Health Sector hearings of the TRC are examined to understand the depth and breadth of the human rights violations that occurred. Issues such as institutionalised violence, racism and inequity in the health care system are discussed. Students are encouraged to reflect on and bring to this session examples from their own experience, both personally and professionally as appropriate, of issues and practices that could be considered an abuse of human rights.

A theme of discrimination in health care and the impact thereof on the health of individuals, families, communities and vulnerable groups deals with many of the challenges facing health care workers. This theme addresses language rights, forcible treatment, HIV/AIDS, confidentiality, sexuality and disability and the rights to information as a mechanism to the realisation of rights (London, 2007: 14). Issues such as unrecognised economic and social rights and the health consequences of underdevelopment are examined. Women's and children's rights as a special category are highlighted, with particular reference to South Africa, where the problems of domestic violence, rape, child abuse and prostitution are part of the daily experiences of many women and children.

The health consequences of sexual abuse, domestic violence, lack of access to sexual and reproductive rights are dealt with by nurses and midwives at all levels of care. The conventions relating to the rights of the child, and elimination of discrimination and of violence against women are examined.

Another theme deals with the health impacts of violence in a number of forms, including societal violence, institutionalised violence (political systems, prisons), armed conflict, torture, and the health status of refugees and displaced persons. The pivotal role of health professionals in documenting and responding to violations and in prevention efforts is highlighted.

A module such as this is designed not merely as a historical and current overview of the topic, but should also facilitate the understanding of current practices and the importance of incorporating human rights into nursing practice. Therefore, the module concludes by identifying situations in which nurses may be vulnerable to human rights abuse or to committing acts which could be considered a human rights violation (e.g. in forensic settings), in order to enable students to develop standards for practice within the workplace (Hannibal et al., 1999: 411-3). The importance of documenting human rights violations and the role of the state institutions supporting constitutional democracy and human rights is highlighted. The role of nurses' organisations in transformation, addressing human rights issues and lobbying for change is emphasised.

\section{Learning activities and assessment}

An ongoing requirement throughout the module is that students scan the media for evidence of human rights violations which have a direct or indirect impact on health, as well as for stories of human rights 'successes'. Students collect articles from newspapers and journals and critically observe the visual media. Their reflections are recorded in a personal journal, in which they are encouraged to link what they read and observe with the relevant human rights documents. This exercise raises awareness of events, policies and actions that directly and indirectly impact on health and human rights.

Further learning activities include analysis of case studies and use of audiovisual clips from the media. Persons with particular backgrounds such as disability and children's rights are invited to share their experiences with the students. Assignments which have to be completed by students in this module include reflective journals in which students are encouraged to think and write about their own experiences and to reflect on the practices in their workplaces. Assessments are formative and summative. The formative assignment is an essay on a human rights and health topic which is followed by a summative assignment of a more practical nature in which the student is required to identify a workplace practice which is in conflict with human rights principles /codes and to devise a practical plan to change the practice.

\section{Can such a module help to change practice?}

Changing practice is difficult; yet, if Mann et al. 's (1999: 8-11) proposition that the promotion and protection of human rights and the promotion and protection of health are fundamentally linked is taken seriously, then health care workers have to begin to make a difference to the health of the individuals and communities that they serve by changing practices which violate human rights.

\section{Reflections of lecturer and students}

As with many new courses, the enthusiasm of the teacher often means that the first offering is pressured and overloaded. 
Such was the case in the presentation of the first module in Health and Human Rights. A number of pioneers in the human rights field contributed to the module, and although students engaged with the issues under discussion, insufficient time was given for them to process the feelings that were generated by the issues. Student tensions were evident in relation to personal experiences - those who had not suffered the indignities of the previous oppressive regime felt that the past was overemphasised, while there were those who felt that their pain was being recognised for the first time. This tension reflects the anxieties which are part of the transition and transformation of South Africa, and required sensitive handling. In the subsequent offering of the module the format was changed to a less pressured content using a case study approach; this has been more accessible and acceptable to the students.

What of the students who took this module? Notwithstanding the difficulties relating to content and process, module evaluations have indicated that the module has been challenging and worthwhile. Student evaluations give some insight into how the students engaged with the issues of health and human rights. Increased awareness of various factors was a theme of the evaluations:

"During this period of exposure to human rights I have become more aware of the complexity of the whole concept."

Awareness of the impact of violation of rights on health:

"I have discovered that it is not possible to talk about what violation of those rights does, without mentioning how they impact on the health of those affected."

Awareness of responsibility for promoting and protecting human rights:

"It is my responsibility as a health professional...to link human rights to my professional accountability through acts geared to ensuring the promotion and protection of human rights."

"Patients have a right to know what is being done to them and what is being said to them. The registered nurse plays a big role in these situations and should be the advocate for the patients at all times."

Moving from awareness to action is an individual process and is more difficult to evaluate during a short module.

\section{Conclusion and recommendations}

The International Council of Nurses position paper on health and human rights states: "Human rights violations have a negative impact on health. It is therefore inconceivable to separate health and human rights, as they need to be integrated into all aspects of health care including policy, programme planning, implementation, monitoring and evaluation. The human rights approach imposes a duty on health care providers and governments and legitimises the rights of populations to have access to health care. A human rights approach also reinforces the ethical principles of equity, the rights to information individual autonomy, beneficence and no doing harm (International Council of Nurses, 1999 1-2). It furthermore provides strategies to address strengthening the link between health and human rights, stating that human rights and ethics education must be mainstreamed into all levels of nursing curricula.

Paul Hunt, UN special rapporteur on the right of everyone to the enjoyment of the highest attainable standard of physical and mental health, states, in Asher (2004) that "health professionals and their professional associations have an indispensable role to play in the vindication of the right to health ... provided that they are equipped with suitable training" (p. iii).

Curricula which include human rights as part of the course content should ensure that the learning context is taken into consideration, and that learners' personal backgrounds and experiences are respected. Learners enter such a course with a wealth of personal understanding and experience, and the nurse educator should be skilled in order to assist the students to engage with their own experiences as they engage with the new content. It is important that the nurse educator is also willing to engage with processes that form the context of his/her own understanding of human rights.

There are enormous challenges facing nursing education in South Africa at this time, as well as facing the health sector in general. Health and human rights are inextricably linked (Mann et al., 1999: 18), and exploration of this link may help to revitalise the health field as well as contributing to broadening human rights thinking and practice. As a society we are judged by our actions towards the most vulnerable, and the health professional is at the forefront of this task.

"Nurse educators should ensure that nursing curricula at the undergraduate, graduate and continuing education levels are regularly updated to meet the needs of the changing healthcare environment" (Maze, 2005: 547). Nurse educators have to meet the challenge of preparing nurses and midwives who are not only accountable and competent in ethical decision-making, but also committed to the promotion of human rights and the facilitation of a human rights culture within the health sector and broader community.

\section{Acknowledgements}

I wish to thank former Truth and Reconciliation Commissioner Glenda Wildschut, Professors Leslie London (University of Cape Town) and Lauren Baldwin-Ragaven (formerly of UCT) for their assistance in the design of the first Health and Human Rights module in 2000. All three persons have an outstanding track record of campaigning for human rights.

\section{References:}

AMNESTY INTERNATIONAL 1997:

Nurses and Human Rights. AL-index: ACT 75/02/1997. http://web.amnesty.org/ aidoc/aidoc_pdf.nsf/Index/ ACT75002 1997ENGLISH/\$File/ ACT7500297.pdf. Accessed 5 May 2006.

AMNESTY INTERNATIONAL 2005: Amnesty International urges a stronger human rights role for nurses and midwives. Nursing Ethics. 12(6):649-650.

ASHER, J 2004: The Right to Health: A Resource Manual for NGOs. London: Commonwealth Medical Trust.

AUSTIN, W 2001: Using the human rights paradigm in health ethics: the problems and the possibilities. Nursing Ethics, 8(3):183-195.

BAI,DWIN-RAGAVEN,L;DEGRUCHY, J \& LONDON, L, eds. 1999: An Ambulance of the Wrong Colour. Health Professionals, Human Rights and Ethics in South Africa. Cape Town: UCT Press.

BALDWIN-RAGAVEN,L; LONDON,L \& DE GRUCHY,J 2000: Learning from our Apartheid Past: human rights chal- 
lenges for health professionals in contemporary South Africa. Ethnicity \& Health. 5(3/4):227-241.

CHAMBERLAIN, M 2001: Human rights education for nursing students. Nursing Ethics. 8(3):21 1-222.

CHAPMAN, A, ed. 1994: Health Care Reform. A Human Rights Approach. Washington: Georgetown University Press.

DEMOCRATIC NURSING ORGANISATION OF SOUTH AFRICA 1997: Submission on nursing by DENOSA to the Truth and Reconciliation Commission. Pretoria: DENOSA

GRUSKIN, S \& TARANTOLA, D 2002: Health and Human Rights. (In Detels, R; McEwen, J; Beaglehole, R \& Tanaka, H, eds. 2002: The Oxford Textbook of Public Health. 4th ed. New York: Oxford University Press: pp. 311-335.

HANNIBAL, K \& LAWRENCE, R 1999: The Health Professional as Human Rights Promoter: Ten Years of Physicians for Human Rights. (In Mann, J; Gruskin, S; Grodin, M \& Annas, G, eds. 1999: Health and Human Rights. A Reader. New York: Routledge: pp. 404-416.

HASSIM, A; HEYWOOD, M \& BERGER, J, eds. 2007: Health \& Democracy: A guide to human rights, health law and policy in post-apartheid South Africa. Cape Town: SiberInk.

HUNT, P 2002: Economic, Social and Cultural Rights. Report of the Special Rapporteur to the 59th Session of the Commission on Human Rights. E/CN.4/ 2003/58. New York: United Nations Economic and Social Council. E/CN.4/2003/ 58.

HUNT, P 2006: The human right to the highest attainable standard of health: new opportunities and challenges. Transactions of the Royal Society of Tropical Medicine and Hygiene. 100(7):603-607.

INTERNATIONAL COUNCIL OF NURSES 1999: ICN Position Statement on Nurses and Human Rights (99/8). Geneva: International Council of Nurses.

INTERNATIONAL COUNCIL OF NURSES 2001: Nurses and Human Rights: International Council of Nurses position statement. Nursing Ethics.
INTERNATIONAL FEDERATIONOF RED CROSS AND RED CRESCENT SOCIETIESAND FRANÇOIS-XAVIER BAGNOUD CENTER FOR HEALTH AND HUMAN RIGHTS 1999: Human Rights: An Introduction. (In Mann, J; Gruskin, S; Grodin, M \& Annas, GJ, eds. 1999: Health and Human Rights. A Reader. New York: Routledge, pp. 46-53.

LONDON, L 2007: 'Issues of equity are also issues of rights': Lessons from experiences in Southern Africa. BMC Public Health, 7:14 [14 pages]. http:// www.biomedcentral.com/1471-2458/7/14 Accessed 30 March 2007.

LONDON, L \& BALDWIN-RAGAVEN, L 2006: Human rights obligations in health care. CME. 24(1):20-24.

LONDON, L \& MCCARTHY, G 1998:

Teaching medical students on the ethical dimensions of human rights: meeting the challenge in South Africa. Journal of Medical Ethics. 24(4):257-262.

MANN, J 1999: Medicine and Public Health, Ethics and Human Rights In MANN, J; GRUSKIN, S; GRODIN, M \& ANNAS, G, eds.: Health and Human Rights. A Reader. New York: Routledge, pp. 439-452.

MANN, J; GOSTIN, L; GRUSKIN, S; BRENNAN, T; LAZZARINI, $Z$ \& FINEBERG, H 1999: Health and Human Rights. (In MANN, J; GRUSKIN, S; GRODIN, M \& ANNAS, G, eds.: Health and Human Rights. A Reader. New York: Routledge: pp. 7-20.

MARKS, S 2003: Health from a Human Rights Perspective. Working Paper No. 14. http://www.hsph.harvard.edu/ fxbcenter/FXBC_WP14-Marks.pdf. Accessed 8 July 2005.

MAZE, CD 2005: Registered Nurses' personal rights vs. professional responsibility in caring for members of underserved and disenfranchised populations. Journal of Clinical Nursing. 14(5):546-554.

NATIONAL DEPARTMENT OF HEALTH SOUTHAFRICA 2002: The Patients' Rights Charter. www.doh.gov.za/docs/legislation/ patientsright/chartere.html. Accessed 7 May 2006.
ORGANISATIONOFAFRICAN UNITY (OAU) 1981: African Charter on Human and Peoples' Rights. OAU Doc. CAB/ LEG/67/3 rev. 5, 21 1.L.M. 58 (1982), entered into force 21 October 1986).

ORGANISATIONOFAFRICANUNITY

(OAU) 1990: African Charter on the Rights and Welfare of the Child, OAU Doc. CAB/LEG/24.9/49 (1990), entered into force Nov. 29, 1999. http://www.africaunion.org/official_documents/ Treaties_\%20Conventions_\%20Protocols/ A.\%20C.\%20ON\%20THE\%20RIGHT\% 20AND\%20WELF\%200F\%20CHILD.pdf. Accessed 20 May 2007.

PHYSICIANS FOR HUMAN RIGHTS no date: The Link between Health and Human Rights. http://www.phrusa.org/ healthrights/link.html. Accessed 15 July 2003.

RUBENSTEIN, LS 2003: Dual Loyalty and Human Rights. Journal of Ambulatory Care Management. 26(3):270-272.

SOUTH AFRICA (REPUBLIC) 1996: The Constitution of the Republic of South Africa (Act No. 108 of 1996). Pretoria: Government Printer.

SOUTH AFRICA (REPUBLIC) 2003: The National Health Act (Act No. 61 of 2003). Pretoria: Government Printer.

SOUTHAFRICAN NURSING COUNCIL 1997: Submission by the South African Interim Nursing Council to the Truth and Reconciliation Commission. Pretoria: SANC.

STEERE, J \& DOWDALL, T 1990: On being ethical in unethical places: the dilemmas of South African clinical psychologists. Hastings Center Report, March/April:11-15.

THETRUTHAND RECONCILIATION COMMISSION 2002: Report of the Truth and Reconciliation Commission, Volume 5. Cape Town, TRC.

THOMPSON, JB 2004: A Human Rights Framework for Midwifery Care. Journal of Midwifery \& Women's Health. 49:175-181.

UNITED NATIONS 1948: The Universal Declaration of Human Rights. Resolution 217 A (III). http://www.unhchr.ch/ udhr/lang/eng.htm. Accessed 17 March 
2000 .

UNITED NATIONS 1966: International Covenant on Economic, Social and Cultural Rights. New York: United Nations.

UNITEDNATIONSGENERALASSEM-

BLY 1975: Declaration on the Rights of Disabled Persons. Resolution 3447 (XXX). New York: United Nations.

UNITEDNATIONSGENERALASSEMBLY 1979: The Convention on the Elimination of all Forms of Discrimination against Women [CEDAW]. New York: United Nations.

UNITEDNATIONSGENERALASSEMBLY 1989: Convention on the Rights of the Child. Resolution 44/25 of 20 November 1989. http://www.ohchr.org/english/ law/pdf/crc.pdf. Accessed 7 May 2006.

WILDSCHUT, G 2001: Human Rights and Nursing. Paper presented at: ICN Ethics Conference, 2001; Copenhagen.

WORLD HEALTH ORGANIZATION 1978: Declaration of Alma-Ata. Geneva: WHO.

WORLD HEALTH ORGANIZATION 1986: The Constitution of the World Health Organisation 1946. (In WHO, ed 1986: Basic Documents. 36th ed. Geneva: WHO.

WORLD HEALTH ORGANIZATION 2001: 25 questions and answers on health and human rights. Geneva: WHO.

WORLD HEALTH ORGANIZATION 2002: Advancing the Dialogue on Health \& Human Rights. Paper presented at: Human Rights Day Commemoration, 2002; Geneva. 